Jian He, Liang He* and Bin Yang*

\title{
Analysis on the impact response of fiber-reinforced composite laminates: an emphasis on the FEM simulation
}

https://doi.org/10.1515/secm-2017-0222

Received June 30, 2017; accepted June 2, 2018; previously published online August 8, 2018

Abstract: The effects of units, material parameters, and constitutive relationships on the dynamic mechanical response of composite laminates subjected to high- and low-velocity impacts were investigated. Additionally, the role of impact or shape, including hemispherical, flat, and conical, on the damage area of the adhesive layer and displacement of the center of the laminated plates was investigated. The results show that the energy absorption of composite laminates increases with impact velocity, and specific energy absorption changes with the density of the contact surface, which is affected by ply thickness. Moreover, the target energy absorption decreases with increasing layer angle. Under a low-velocity impact, the maximum contact force, damage area of the adhesive layer, and displacement of the center of the laminated plate increase as the impact energy increases, thus showing that impact energy is not directly related to contact duration and energy absorption of composite laminates. The results of different geometric shapes show that the damage area of the adhesive layer and the displacement of the center of the laminated plates are largest for a conical impactor and smallest for a flat impactor.

Keywords: dynamic response; energy absorption; laminated composites; numerical simulation.

\section{Introduction}

As a kind of lightweight material, composite materials are widely used in bulletproof $[1,2]$ and aerospace fields $[3,4]$. Research on composite materials damage under

\footnotetext{
*Corresponding authors: Liang He, College of Aerospace and Civil Engineering, Harbin Engineering University, Harbin, China, e-mail: heliang@hrbeu.edu.cn; and Bin Yang, School of Mechanical and Power Engineering, East China University of Science and Technology, Shanghai, China, e-mail: yangbin@ecust.edu.cn Jian He: College of Aerospace and Civil Engineering, Harbin Engineering University, Harbin, China
}

Әopen Access. (c)

(c) 2019 Walter de Gruyter GmbH, Berlin/Boston high-velocity impact has theoretical and practical significance for military preparedness [5]. Composite materials will inevitably face unexpected collisions during use. Obvious damage may not be found on the surface under low-velocity impacts, although the composite laminates may suffer internal delamination damage. This internal damage will greatly influence the material's mechanical properties and lead to the decline of the material bearing capacity [6]. Therefore, it is valuable to study the impact response of fiber-reinforced composite laminates.

Considerable effort has been made in analyzing the damage modes and the impact response of composite materials. Yang et al. [7] built a 3-D finite element model (FEM) to investigate the high-velocity impact response of fiber-metal laminates (FMLs) using ABAQUS/Explicit platform; the results showed that the effect of fiber stacking sequence on the impact performance of FMLs is very limited under critical penetration velocity, and the damage pattern depends on the projectile incident angle. In reference [8], they also verified their mode of interply hybrid composites based on woven fabrics and polymerized cyclic butylene terephthalate resin subjected to low-velocity impact. Long et al. [9] established a damage analysis process of composite laminates subjected to low-velocity impact by building numerical models on a damage model where cohesive contact method was involved according to the experimental observation. Based on the results obtained, they presented a prediction process of delamination shape for composite laminates under low-velocity impact. Zhang et al. [10] proposed a FEM to investigate the dynamic mechanical response and damage modes in cross-ply composite laminates under transverse lowvelocity impact. By adopting Hashin criterion and a gradual degradation scheme, the simulation results agree well with the available experimental data. Using the proposed model, they also investigated the effect of interface friction on the delamination response of cross-ply composite laminates under impact. Zhang and Zhang [11] built a simplified and efficient FEM with the delamination damage adjacent to the mid-thickness plane and the lower face taken into consideration to study the impact response and corresponding damage mode of composite laminates subjected to low-velocity impact. The proposed model can 
deliver acceptable prediction of the critical impact force and damage shape and size. In addition, foam-filled sandwich panels with six types of facesheets were manufactured by Yang et al. [12], and the low-velocity impact test and compression after impact test of the prepared panels were performed. They found that the stacking sequence of fabric clothes has some effects on the impact properties of the hybrid panels.

The paper is organized as follows: section 1 introduces the research background. In section 2, the dynamic response of laminated composites under high-velocity impact is analyzed using the finite element software LS-DYNA, which simulated the laminated plate with a SHELL163 unit without considering the bonding layer, using CHANG-CHANG criterion as the constitutive model. The effects on the energy absorption of the composite laminates, which were produced by the impact velocity, target thickness, and ply angle, were analyzed in detail. In section 3, the low-velocity impact dynamic response of composite laminates was studied. The laminated board layer was simulated with a SOLID164 unit, and the adhesive layer was simulated with a SOLID ELEMENT No. 19 unit, using CHANG-CHANG criterion as the constitutive model. The effects on laminates bonded layer damage and energy absorption, produced by the bonding layer damage development, sub-layer stress change of different ply angles, impact energy, and punch shape, were analyzed in detail. Section 4 concludes the paper.

\section{Dynamic response of composite laminates under high-velocity impact}

\subsection{Damage criterion of laminates}

Compared with isotropic materials, the failure modes of composite materials under impact loads are much more complex because of not only the complexity of composite strength itself but also the characteristics of multiphase combinations. From a microscopic angle, laminate damage is mainly divided into three categories. First is the fiber fracture which is dominated by fiber damage, including fiber breakage and micro buckling. Second is the matrix cracking, which is dominated by matrix damage, including meso-cracks and holes. Third is the spatial delamination fracture, including the interface debonding and crack propagation. Fiber breakage and matrix cracking occur mainly inside the composite single plate, while delamination damage occurs mainly within the composite sub-layers. In this paper, the CHANGCHANG failure criterion is selected based on the LS-DYNA.

$$
\left\{\begin{array}{l}
\text { fiber fracture failure }\left(\sigma_{11}>0\right) \\
\left(\sigma_{11} / X_{T}\right)^{2}+\bar{\tau}=1 \\
\text { matrix crack failure }\left(\sigma_{22}>0\right) \\
\left(\sigma_{22} / Y_{T}\right)^{2}+\bar{\tau}=1 \\
\text { matrix compression failure }\left(\sigma_{22}<0\right) \\
\left(\frac{\sigma_{22}}{2 S}\right)^{2}+\left[\left(\frac{Y_{c}}{2 S}\right)^{2}-1\right]\left(\frac{\sigma_{22}}{Y_{C}}\right)+\bar{\tau} \geq 1
\end{array}\right.
$$

where $\bar{\tau}=\left(\frac{\tau_{12}}{S}\right)^{2} \frac{1+\frac{3}{2} \alpha G_{12} \sigma_{12}^{2}}{1+\frac{3}{2} \alpha G_{12} S^{2}}, X_{T}, Y_{T}$, and $Y_{C}$ represent the longitudinal tensile strength, the transverse tensile strength, and the transverse compression strength, respectively. $\alpha$ is a constant determined by experiment, and $\alpha=0$ when considering linear elasticity only.

\subsection{The finite element model}

In the finite element simulation, a 7.62-mm handgun bullet is used, and the bullet head is simplified as a hemisphere. The SOLID164 unit and the MAT_RIGID model are employed. SOLID164 is an eight-node unit with three degrees of freedom, and the bullet head contains 500 elements. In the process of impact, the bullet is regarded as an ideal rigid material without deformations. The material parameters are shown in Table 1.

The laminated plate size is $60 \mathrm{~mm} \times 60 \mathrm{~mm}$, simulated by the specific SHELL163 unit of ANSYS/LS-DYNA. SHELL163 is a four-node unit with six degrees of freedom. The model is chosen from the material library, and the material parameters are shown in Table 2. Considering both calculation precision and run time, only one fourth of the complete model is put forward in this paper since the model is symmetric, and the plate contains 800 elements. During the simulation, the processing time varies from $0.5 \mathrm{~h}$ to $1 \mathrm{~h}$ and depends on the incident velocities.

The target plate is subdivided into the bullet shooting region, and the remaining region is relatively rougher. The grid size in the bullet contact center region is $1 \mathrm{~mm}$,

Table 1: Material parameters of bullet.

\begin{tabular}{lrrr}
\hline Density $\left(\mathrm{g} / \mathrm{cm}^{3}\right)$ & Young modulus (Gpa) & Poisson's ratio & Mass (g) \\
\hline 7.85 & 207 & 0.3 & 5.8 \\
\hline
\end{tabular}


Table 2: Material parameters of composite.

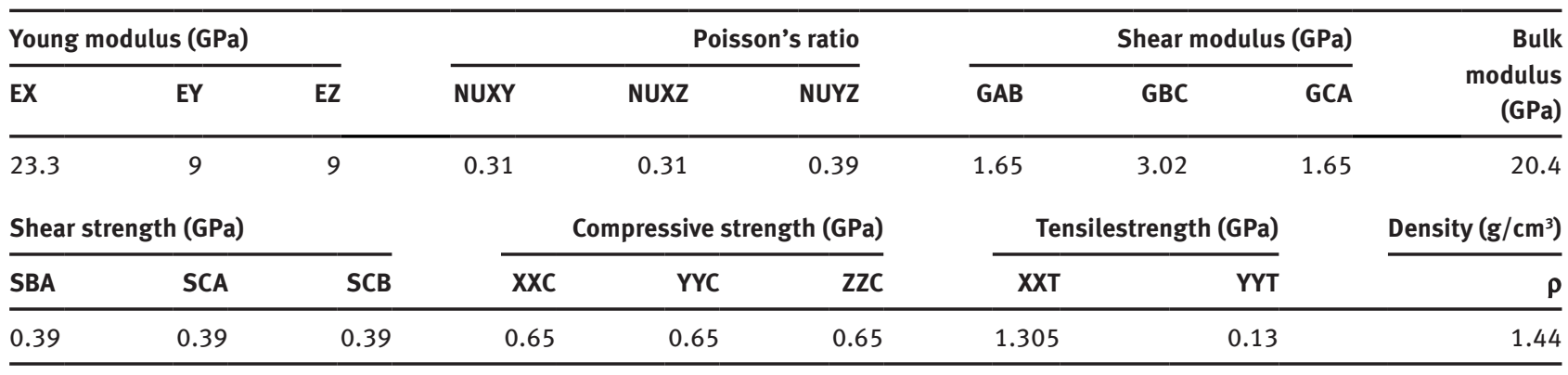

and the remainder of the area has a grid size of $2 \mathrm{~mm}$, as shown in Figure 1.

\subsection{Analysis of the numerical simulation results}

In order to verify the proposed simulation method, we consider the work of Aymerich et al. [13]. According to the experiments, the laminate is simulated with the angle ply sequence [0/90/0/90/0/90/0/90/0/90].
The cylindrical bullet diameter is $7.62 \mathrm{~mm}$, with an aspect ratio of 2 . The target size is $20 \mathrm{~cm} \star 90 \mathrm{~cm}$, and the thickness is $5 \mathrm{~mm}$. In our simulation, the impact energy is handled by assigning different velocities to the impactor. Simulations are performed with the velocities of $246.6 \mathrm{~m} / \mathrm{s}, 300.2 \mathrm{~m} / \mathrm{s}, 388.8 \mathrm{~m} / \mathrm{s}, 471.2 \mathrm{~m} / \mathrm{s}$, and $551.5 \mathrm{~m} / \mathrm{s}$, respectively.

The comparison of bullet residual velocity from the numerical simulation and experimental results are listed in Table 3. It can be seen that the user-defined material numerical results match the experimental results, which
A
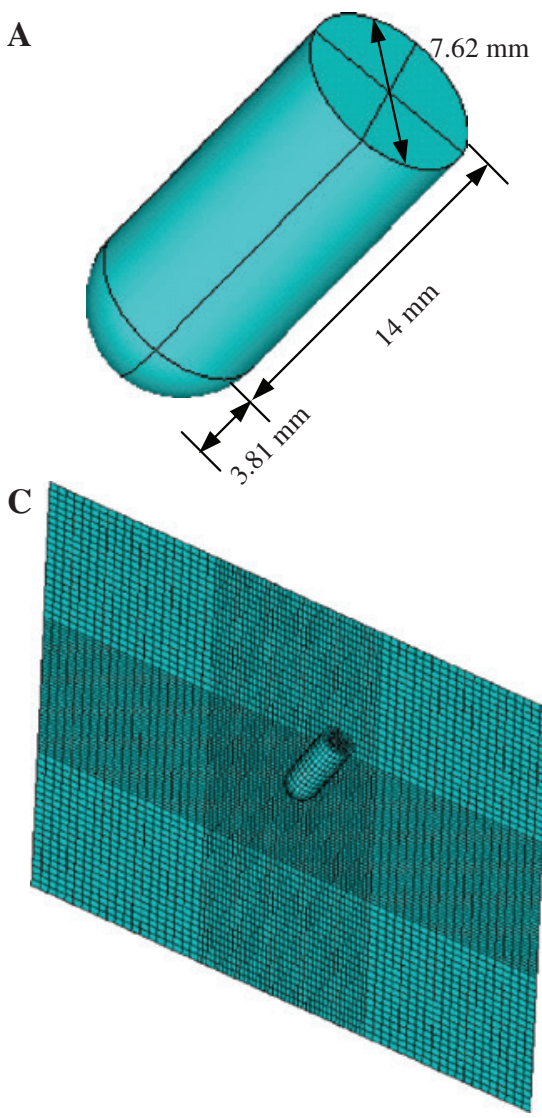

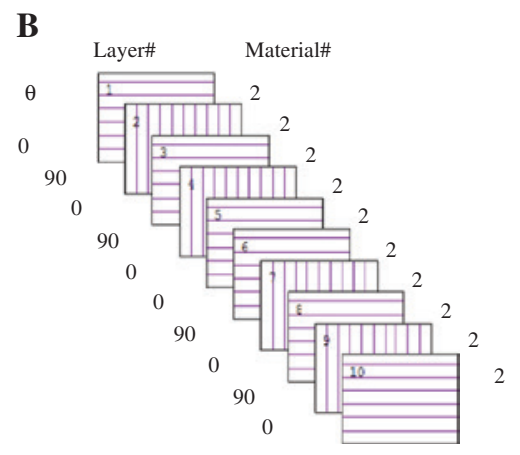

D !

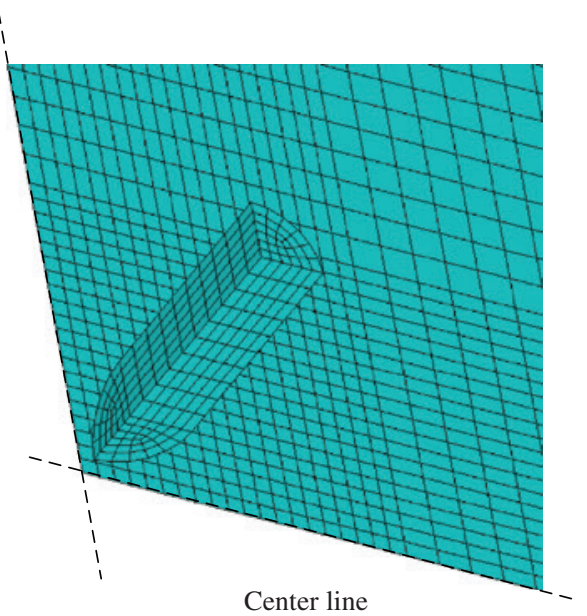

Figure 1: Finite element model of the laminated plates under bullet impact. (A) Bullet model, (B) ply situation, (C) global grid, and (D) local grid. 
Table 3: Comparison of bullet residual velocity numerical simulation results and experimental results.

\begin{tabular}{|c|c|c|c|c|c|}
\hline Bullet velocity (m/s) & 246.6 & 300.2 & 388.8 & 471.2 & 551.5 \\
\hline Bullet residual velocity (m/s) & 62.6 & 190.7 & 302.4 & 416.9 & 498.1 \\
\hline Numerical simulation results $(\mathrm{m} / \mathrm{s})$ & 50.1 & 178.6 & 287.3 & 392.6 & 475.2 \\
\hline
\end{tabular}

illustrates that the numerical simulation method in this paper is effective.

\subsubsection{Anti-ballistic properties of composite materials against different impact velocities}

The anti-ballistic performance of composite materials depends greatly on the velocity effect, which means that in a certain range of velocity, the energy-absorbing capacity may increase with the velocity of the bullet [14]. In the simulation, the one-fourth bullet model penetrates the target at speeds of $200 \mathrm{~m} / \mathrm{s}, 250 \mathrm{~m} / \mathrm{s}, 300 \mathrm{~m} / \mathrm{s}, 350 \mathrm{~m} / \mathrm{s}$, $400 \mathrm{~m} / \mathrm{s}$, and $450 \mathrm{~m} / \mathrm{s}$, while the other conditions remain unchanged. Figure 2 shows the kinetic energy variation curve of the bullet at different initial velocities.

In order to analyze the relationship between bullet velocity and target plate absorption energy, the relationship between bullet velocity and kinetic energy loss is shown in Figure 3. It can be observed in Figure 3 that in the velocity ranging from $200 \mathrm{~m} / \mathrm{s}$ to $450 \mathrm{~m} / \mathrm{s}$, kinetic energy loss increases with increasing bullet velocity. This finding illustrates that target energy absorption will increase as the initial velocity increases in a certain range, demonstrating the energy absorption speed effect mentioned previously.

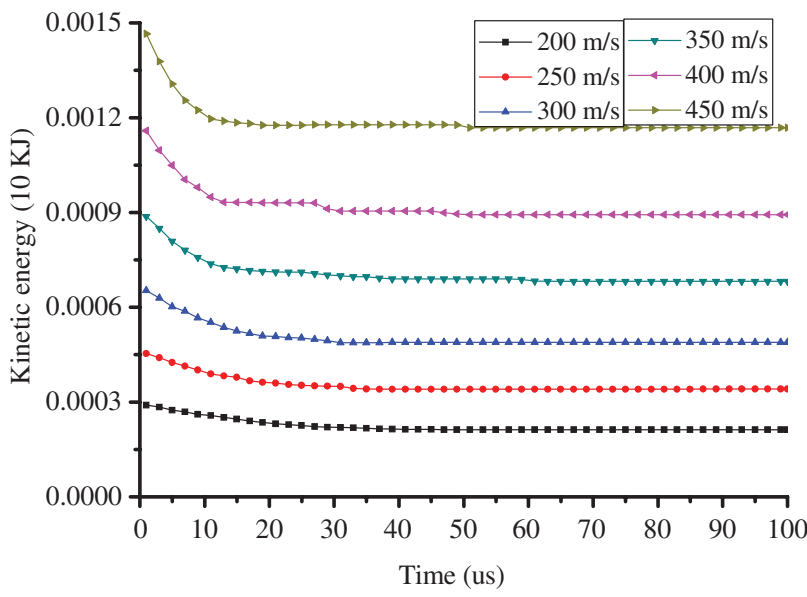

Figure 2: Bullet kinetic energy-time curves with different impact velocities.

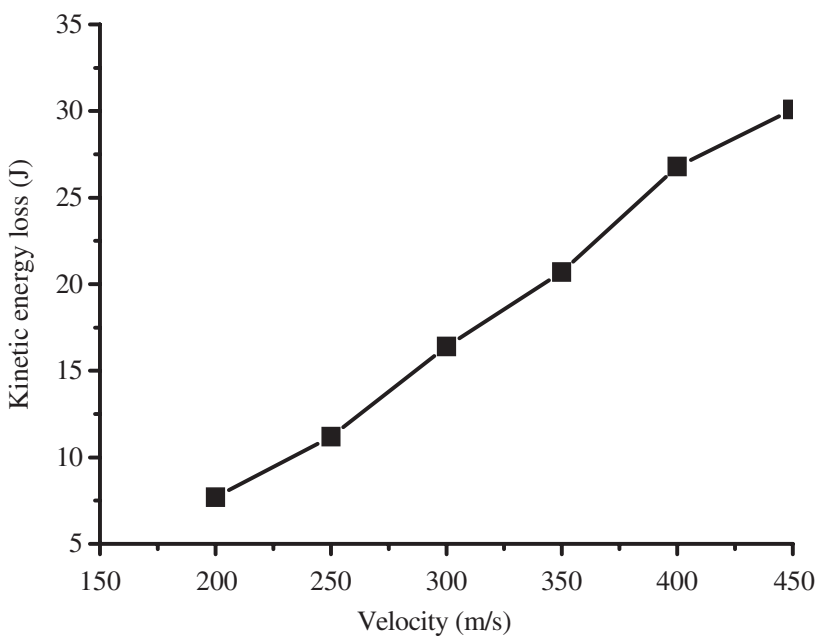

Figure 3: Bullet velocity-kinetic energy reduction curve.

\subsubsection{Relationship analysis between target plate thickness and energy absorption effect}

It is generally recognized that the area density of the fiber composite laminate is directly related to its energyabsorbing capability. The area density is the quality per unit area in the penetration direction. The area density is related to both the material characteristics and the target board thickness [15]. Since the laminated composite material remains constant in this paper, when target thickness changes, the reduction of kinetic energy under different plate thicknesses can be obtained, which is approximately equal to the energy absorbed by the target board.

Figure 4 shows the bullet kinetic energy loss curves for the target thicknesses of $1 \mathrm{~mm}, 2 \mathrm{~mm}, 3 \mathrm{~mm}, 4 \mathrm{~mm}$, and $5 \mathrm{~mm}$, respectively. It can be observed that, with all other conditions kept constant, bullet residual velocity reduces from $293.01 \mathrm{~m} / \mathrm{s}$ to $180 \mathrm{~m} / \mathrm{s}$ with the increase in plate thickness. With the increase in area density, the loss of bullet kinetic energy, which is approximately equal to the target energy absorption, increases from $12 \mathrm{~J}$ to $164.32 \mathrm{~J}$. This response occurs mainly due to the fact that the increased target thickness leads to higher energy consumption in the penetration process. Relevant literature indicates that the specific energy absorption is an important standard to measure the material energy 


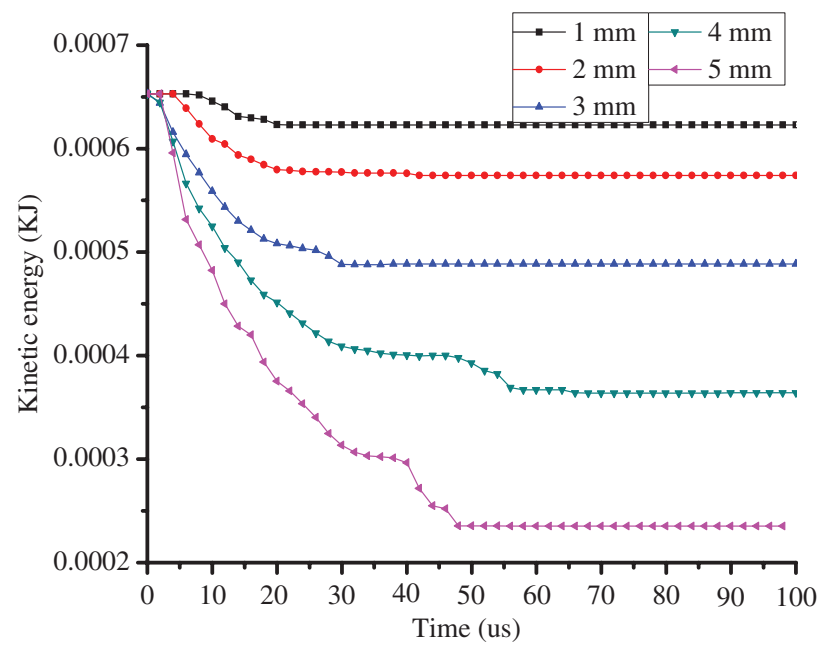

Figure 4: Bullet kinetic energy reduction-time curves for target plates with different thicknesses.

absorption ability, which measures the quality of materials' anti-ballistic properties using the ratio of target energy absorption to area density [16].

Figure 5 shows the change of specific energy absorption for the target plate thicknesses ranging from $1 \mathrm{~mm}$ to $5 \mathrm{~mm}$. The specific energy absorption increases as the target thickness increases. The specific energy absorption increases sharply when the target is thinner and tends to flatten when the target is thicker. This can be explained by the fact that the size of the target is close to the bullet size, the energy produced in penetration cannot be ignored, and it does not belong in the category of thin plate.

\subsubsection{Relationship analysis between the ply angle and target plate energy absorption}

For composite materials, different ply directions may lead to different mechanical properties. In order to investigate how the degree of anisotropy influences the composite energy absorption, the 3-mm composite plate is subjected to different penetration angles under the same speed of $300 \mathrm{~m} / \mathrm{s}$. Figure 6 shows the one-fourth bullet kinetic energy reduction trend under ply angles $[0]_{8},[30]_{8},[45]_{8}$, and $[60]_{8}$.

At ply angle $[0]_{8}$, the bullet loses the most kinetic energy, signifying the best anti-ballistic performance. On the contrary, at ply angle $[60]_{8}$, the bullet loses the least kinetic energy. The laminate energy absorption decreases as the ply angle increases with other conditions unchanged, as shown in Figure 7. This is due to the fact that the increase in ply angle reduces the strain rate strengthening effect; thus, the dynamic mechanical properties are deteriorating [17]. In addition, as the ply angle

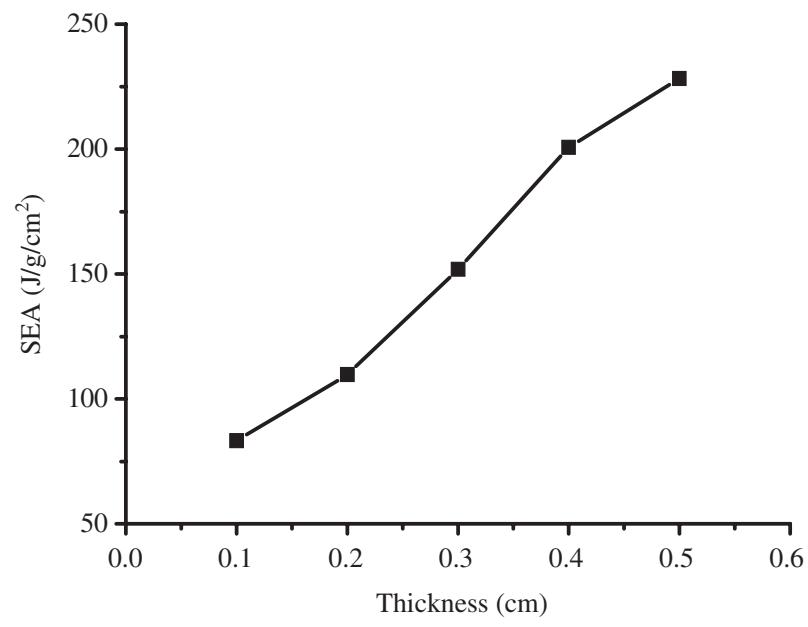

Figure 5: Target plate thickness-specific energy absorption curve.

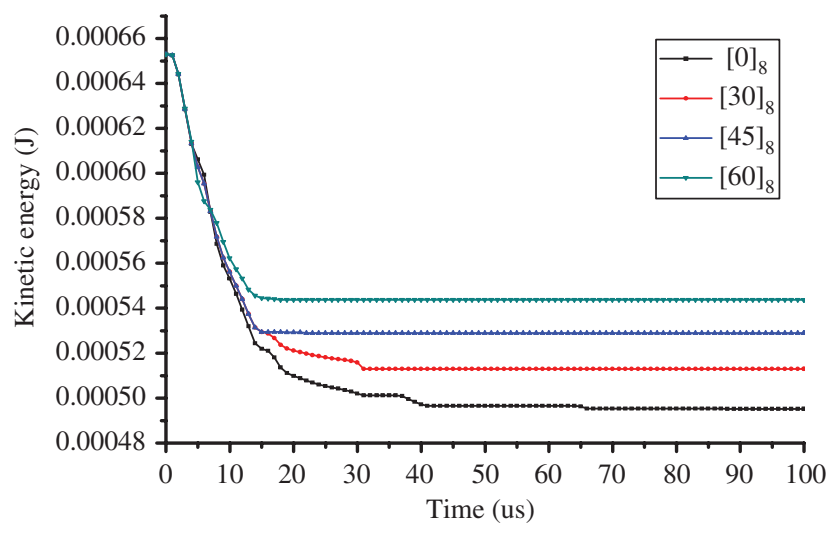

Figure 6: Bullet kinetic energy-time curves with different layer angles.

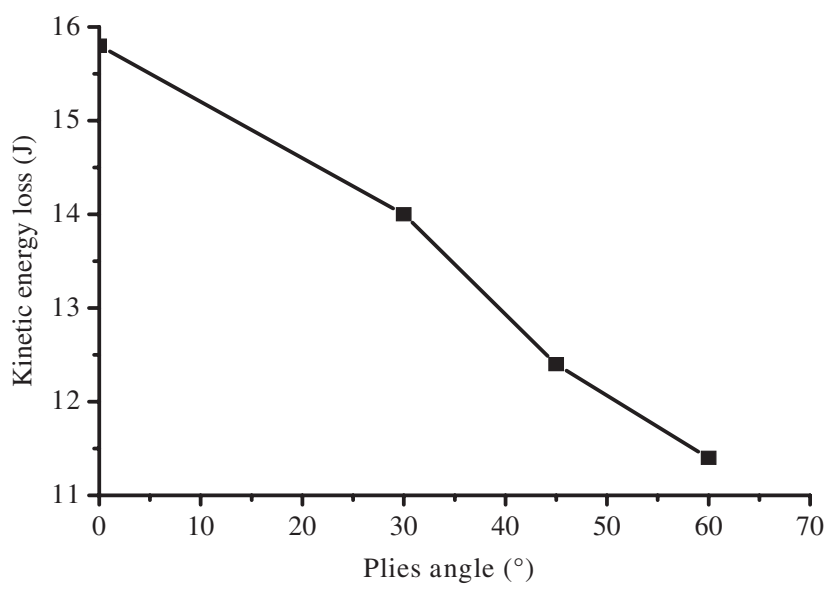

Figure 7: Ply angle-bullet kinetic energy damage curve.

increases, the reflection of the shock wave in the crossing point increases and the decreased impact response area is not conducive to the spread of energy, thus reducing the 
anti-ballistic properties of the laminates. To summarize, the laminate ply angle has substantial influence on the absorbed energy.

By comparing the damage results under different ply angles, it can be found that the breakage shape is approximately an ellipse when ply angle is 0 , and the fiber direction is along the short axis because of the orthotropic characteristics of the composite materials. It demonstrates that the mechanical property along the fiber direction is higher than that along its vertical direction. According to the damage pattern obtained from the numerical results, the damage shape of composite laminates changes from an ellipse to a circle as the ply angle changes.

\section{Damage response of composite laminates subjected to low-velocity impact}

\subsection{Damage model of composite laminates subjected to low-velocity impact}

In simulation, LS-DYNA is used to simulate and compute the impact. CHANG-CHANG failure criterion is selected as the sub-layer failure criterion, and the E material model for the new version of LS-DYAN program is used in this paper, which is extended from the CHANG-CHANG criterion. The formula expression is as follows:

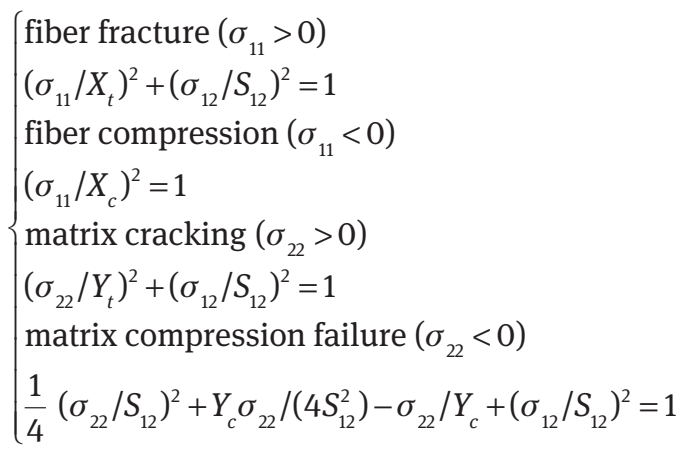

A number of experimental studies have illustrated that the delamination damage in composite laminates generally arises between the sub-layers that undergo ply angle changes. To address this concept, a thin layer of interface element layer can be added between the anglechanged sub-layers in the numerical simulation. Then, the delamination damage of composite laminates can be simulated through the interfacial layer damage failure. The interface layer is shown in Figure 8.

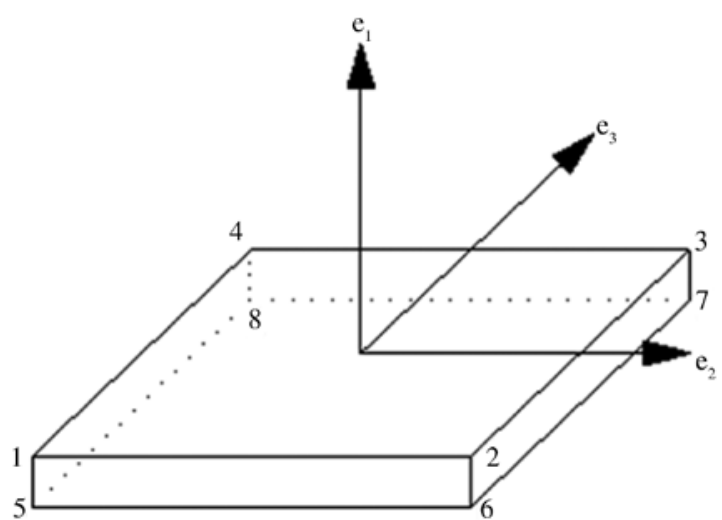

Figure 8: Interface element model.

The selected SOLID ELEMENT 19 unit is based on COHESIVE ZONE theory, mainly considering the interfacial force $P_{i}(i=1,2,3)$ and the displacement relationship between the top and bottom surfaces $\left[P_{i}=k_{i}\left(\delta_{i}\right)\right.$ and $\left.\delta_{i}(i=1,2,3)\right]$. The bilinear constitutive model is adopted, as shown in Figure 9.

In practical applications, re-coupling or the linear coupling criteria are used as the basis of judgment for a bonding layer crack, as expressed in Equation (3), in which the coefficients $\operatorname{GiC}(i=a, b$, and $c)$ represent the critical energy release rates of three types of cracks.

$$
\begin{aligned}
& f_{g}=\left(G_{a} / G_{a C}\right)^{2}+\left(G_{b} / G_{b C}\right)^{2}+\left(G_{c} / G_{c C}\right)^{2} \\
& f_{g}=G_{a} / G_{a C}+G_{b} / G_{b C}+G_{c} / G_{c C}
\end{aligned}
$$

\subsection{Numerical simulation of composite materials subjected to low-velocity impact}

(2) In Ref. [13], the experiment of composite materials subjected to low-velocity impact was simulated. The ply angle was designated as [0/90/0/90/0/90/0/90/0/90], and the laminate was hinge-constrained with a size of $87.5 \mathrm{~mm} \times 65 \mathrm{~mm} \times 2 \mathrm{~mm}$ and effective center area with size
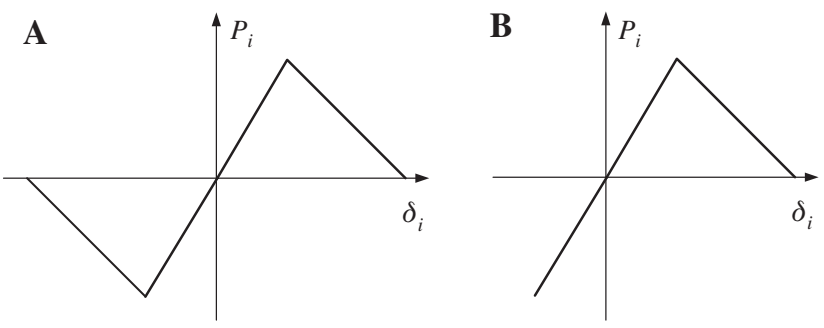

Figure 9: Bonding layer simplified bilinear model. (A) Shear model. (B) Normal model. 
Table 4: Material parameters of sub layer with 0 ply angle

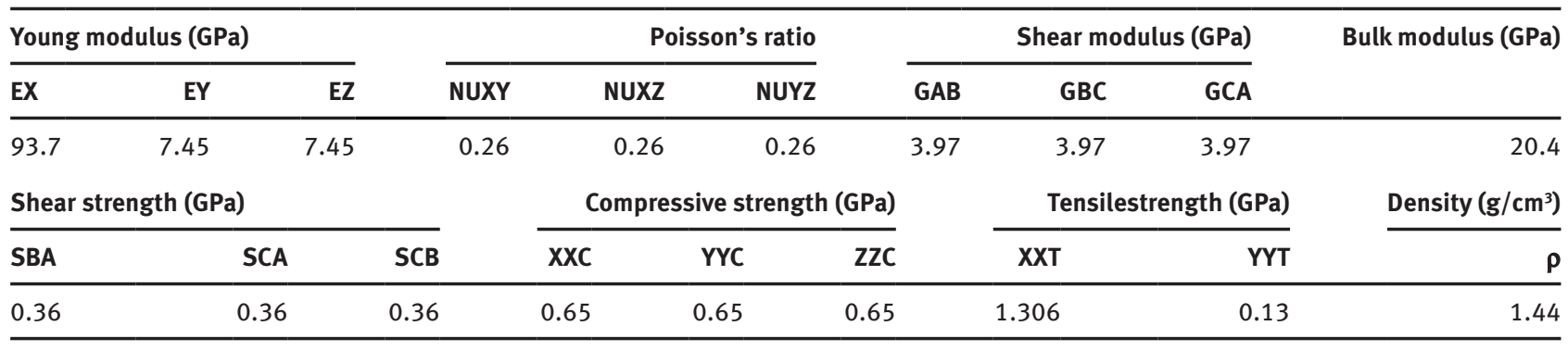

of $67.5 \mathrm{~mm} \times 45 \mathrm{~mm}$. The experimental rigid hemispherical punch has the radius of $0.625 \mathrm{~cm}$ and a density of $7.8 \mathrm{~g} / \mathrm{cm}^{3}$. In order to reduce the finite element running time, the simulation used a one-fourth model of the punch with a SOLID164 solid element.

A SOLID164 element is also used to simulate laminated sub-layers. Three single plates with 0 ply angle were modeled as one sub-layer. A six-layer single plate with a 90 ply angle layer in the middle was modeled as one sub-layer. A three-layer single plate with a 0 ply angle was modeled as one sub layer. The material parameters to model 0 ply angle layers are shown in Table 4, and they can be multiplied by a stiffness transformation matrix to obtain parameters to model for the 90 ply angle layers.

Improved CHANG-CHANG failure criterion is used as sub-layer damage failure criterion. An interface layer is inserted between the sub-layers with changing ply angles, forming a laminated structure. Furthermore, an adhesive layer is simulated with specific material unit COHESIVSOLID ELEMENT 19 element in the LS-DYNA971 version. Constraints between top and bottom layers are established to ensure the continuity of the whole model movement. The new model is applied to build a bonding layer model, using the bilinear material model. In order to simplify the calculation, it is assumed that the shear stresses in the two directions on the interface are the same due to the same constitutive model. Moreover, both the tearing type and the sliding type of cracking mode have the same critical release rate, which can be calculated from Equation (3). The following equation can be derived.

$$
k_{2}=k_{3}, G_{b C}=G_{c C}, f_{g}=\left(G_{a} / G_{a C}\right)^{2}+\left(G_{b} / G_{b C}\right)^{2}
$$

In order to precisely obtain the dynamic response of laminates subjected to low-velocity impact, the meshes of the impact region are refined, particularly in the rectangular region of $X[0 \mathrm{~mm}, 15 \mathrm{~mm}], Y[0 \mathrm{~mm}, 10 \mathrm{~mm}]$, as shown in Figure 10.

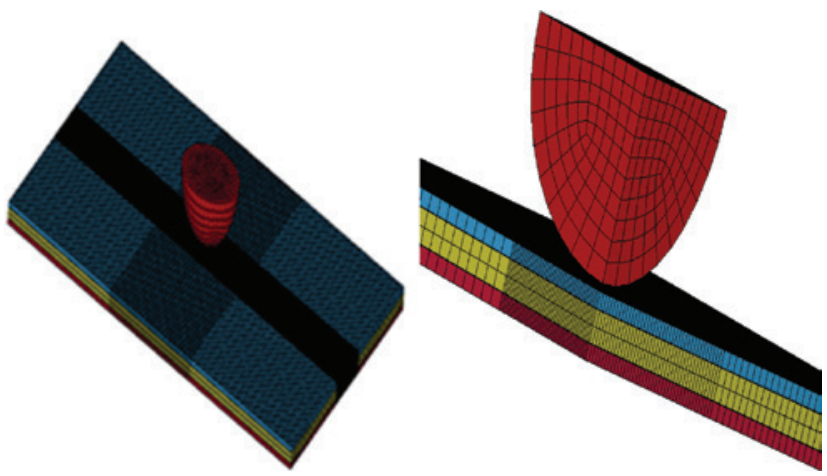

Figure 10: Geometric modeling diagram.

\subsection{Analysis of the simulation result}

To compare the simulation results with the experimental results, the delamination damage chart of the bottom layer and the impact contact force time curve are shown in Figure 11.

\subsubsection{Damage and extension on bonding layer}

The bonding layer can be damaged easily under lowvelocity impact when the direction of the fiber changes. At the same time, the area and shape of the damage as well as the strain should be approximately the same. It is convenient and clear to observe the process of layered production, extension, and evolution of damage by the postprocessing method in simulation, as shown in Figure 12.

\subsubsection{Plate stress under low-velocity impact}

It can be found that the stress nephogram exhibits a peanut-shaped profile for both conditions (layer angle $0^{\circ}$ or $90^{\circ}$ ), and the main axis's direction of the peanutshape nephogram is perpendicular to the layer angle of the sub-layer. This observation is consistent with the 


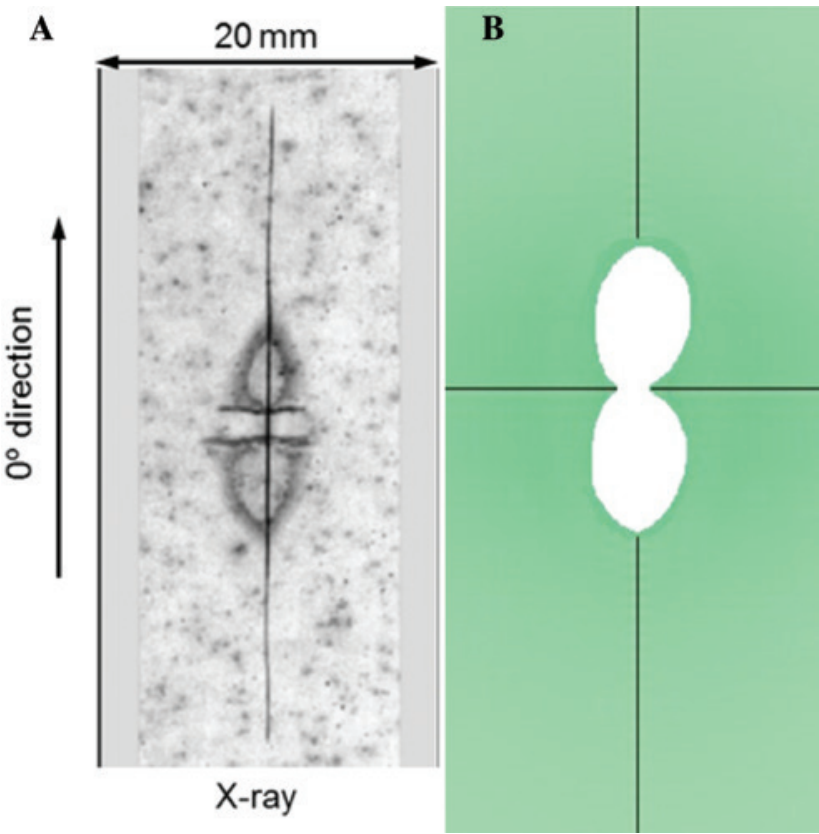

Figure 11: The time curve of the impact contact force of the laminate plate for experiment and simulation. (A) The layered damage for experiment in Ref. [13]. (B) The damage of adhesive layer for simulation.

experimental phenomenon. As time elapses, the strain transfers towards both sides, and the damage increases, as shown in Figure 13.

\subsubsection{Damage analysis under different impact energies}

In this section, five groups of punches with different initial energies are set up to impact the laminate to investigate the corresponding damages. The results are shown in Table 5.

As shown in Figure 14, the peak of the impact load increases as the impact energy increases. Within a certain range, the increased punch energy caused by the mass effect affects the contact time between the punch and laminated plate. Moreover, this finding also shows that the duration time of the impact does not change after the energy reaches a certain value.

\subsubsection{Effect of impact energy on the damage area and plate center displacement}

As shown in Figures 15 and 16, within a certain range, when impact energy increases, the damage area of the adhesive layer and the displacement of the plate center increase in an approximately linear manner.

\subsubsection{Effect of impact energy on energy absorption of laminated plate}

Compared with high-velocity impact, the energy damage of the punch under low-velocity impact is relatively small, as shown in Figure 17. Besides, the damage energy of the punch and the energy absorption of the target plate exhibit small changes for different impact energies. The results show that the initial energy is not the main factor that affects the laminated plate during the low-velocity impact.
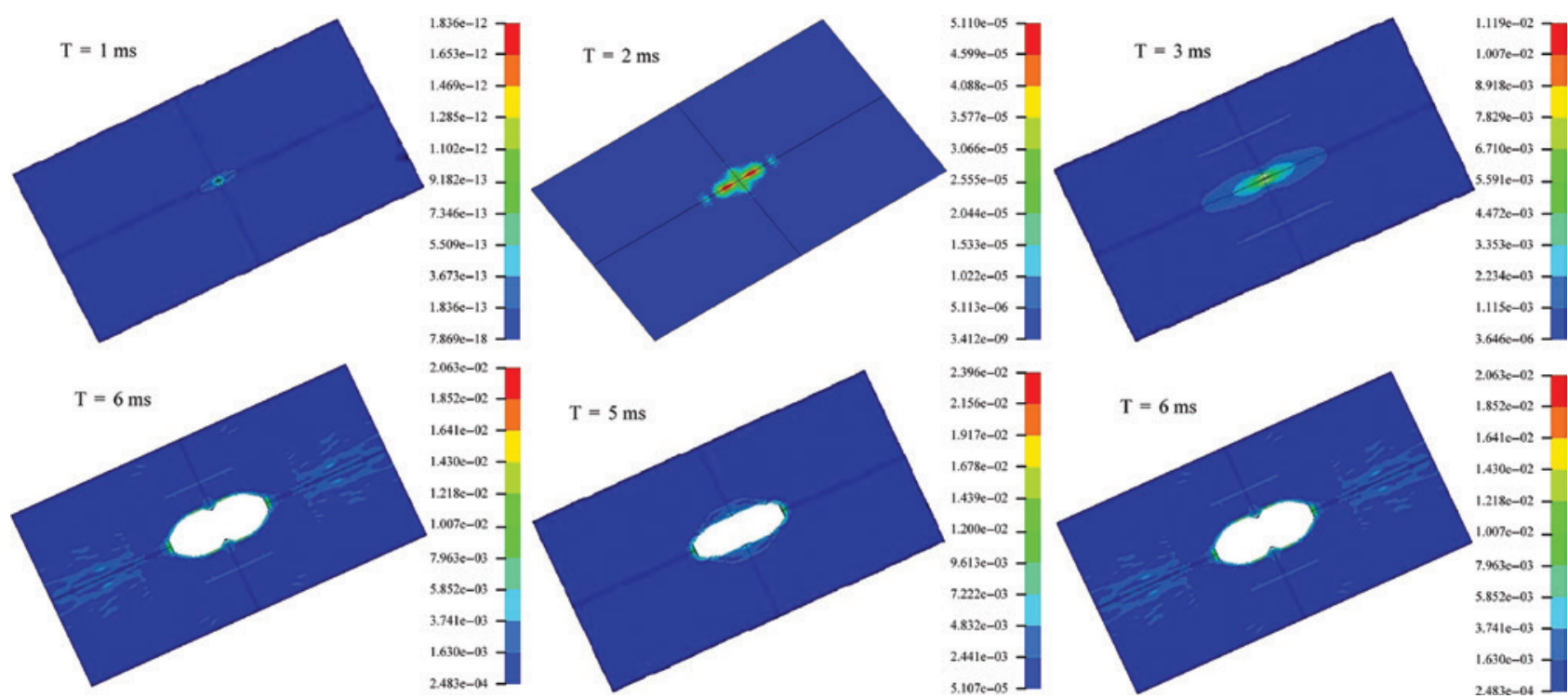

Figure 12: The damage of the adhesive layer. 

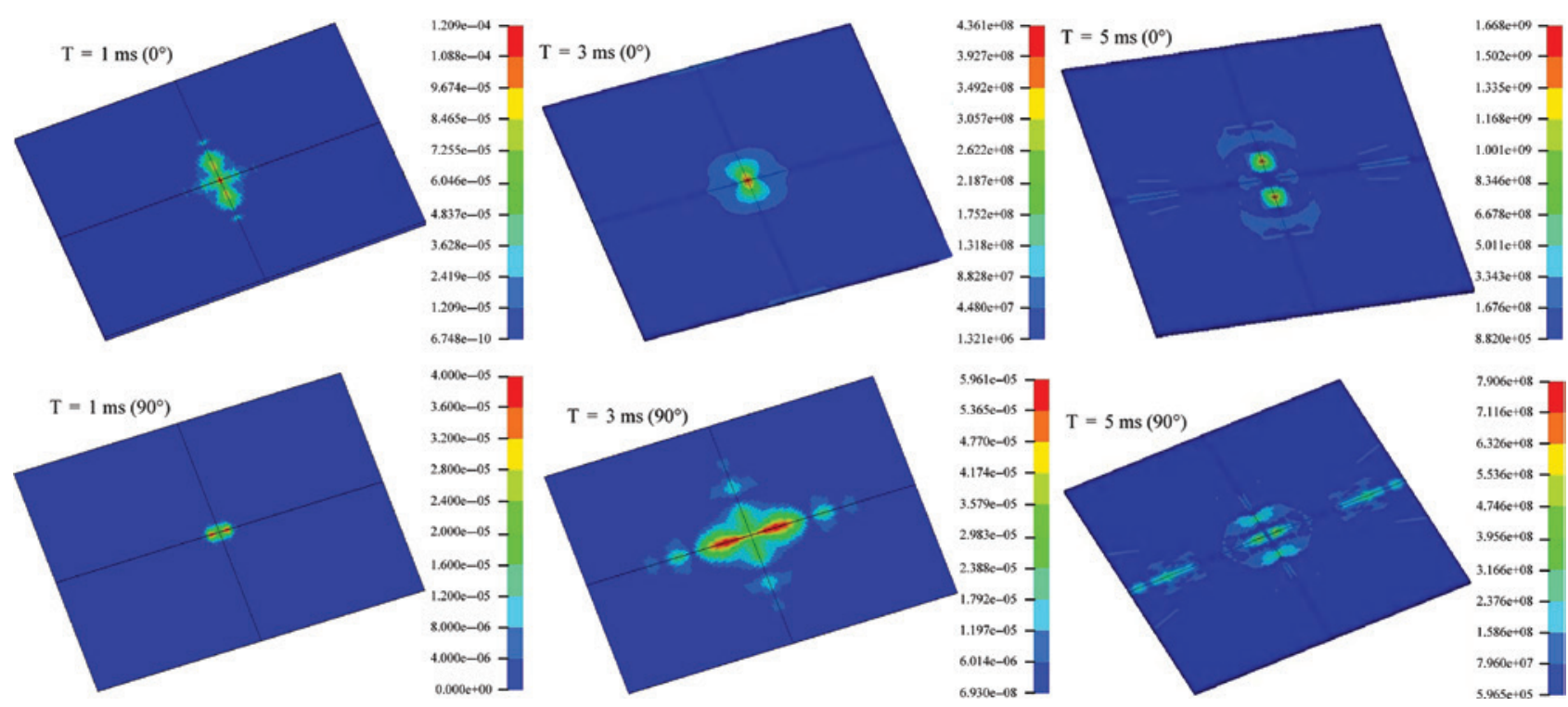

Figure 13: The Von Mises stress at different times.

\subsubsection{Effect of punch shapes on the response of the plate under low velocity}

In this paper, three kinds of punches with different shapes are used to analyze the response of the plate under lowvelocity impact, as shown in Figure 18. All of the punches have the same mass, radius, and initial impact energy.

Table 5: Conditions of calculation.

\begin{tabular}{lrr}
\hline Impact energy $(\mathrm{J})$ & Punch mass (kg) & Impact velocity $(\mathrm{m} / \mathbf{s})$ \\
\hline 1.983 & 1.9 & 1.444 \\
2.191 & 2.1 & 1.444 \\
2.4 & 2.3 & 1.414 \\
2.7 & 2.3 & 1.532 \\
3 & 2.3 & 1.615 \\
\hline
\end{tabular}

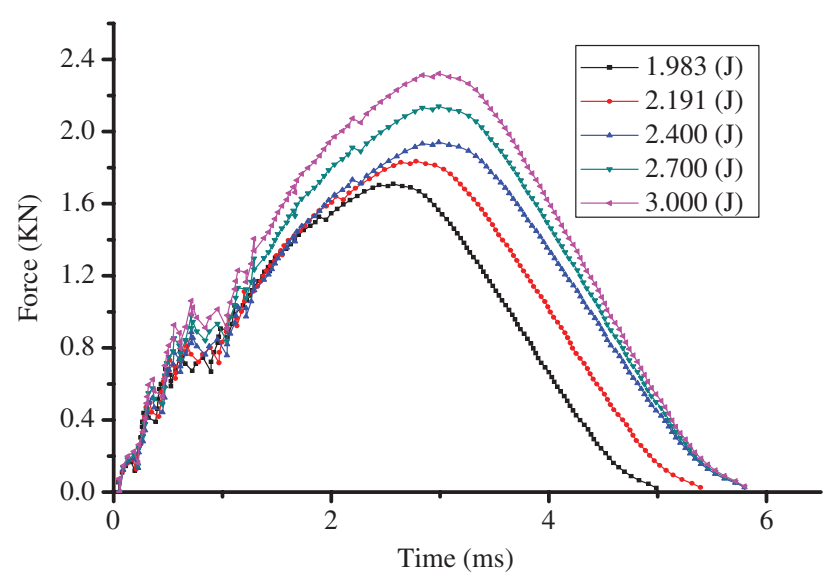

Figure 14: Time curves of contact force under different impact energies.
Figure 19 shows the variations of contact force as a function of time for different types of impactors. As seen, the laminated plate impacted by a flat punch is the first to reach the maximum contact force, while the plate impacted by a conical punch is damaged last. In contrast, the laminated plate impacted by a flat punch bears the highest maximum contact force, while the conical punch bears the lowest. Because it takes the longest time to achieve maximum contact force, it gets the most serious damage among these three conditions. The following conclusion can be drawn: Incisive punch causes severe damage to the plate.

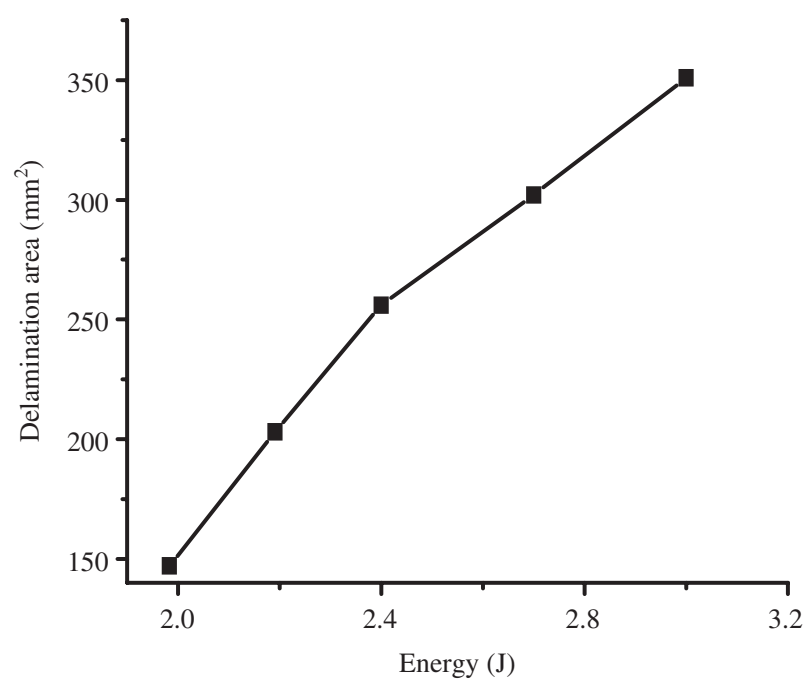

Figure 15: The variations of delamination area as a function of energy. 


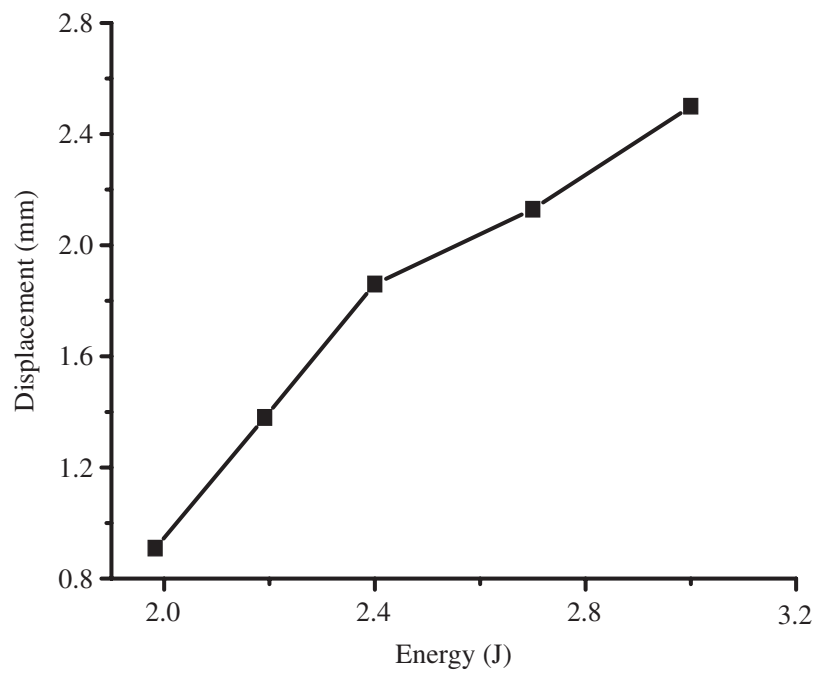

Figure 16: The curve between the impact energy and damage area of the adhesive layer and displacement at the plate center.

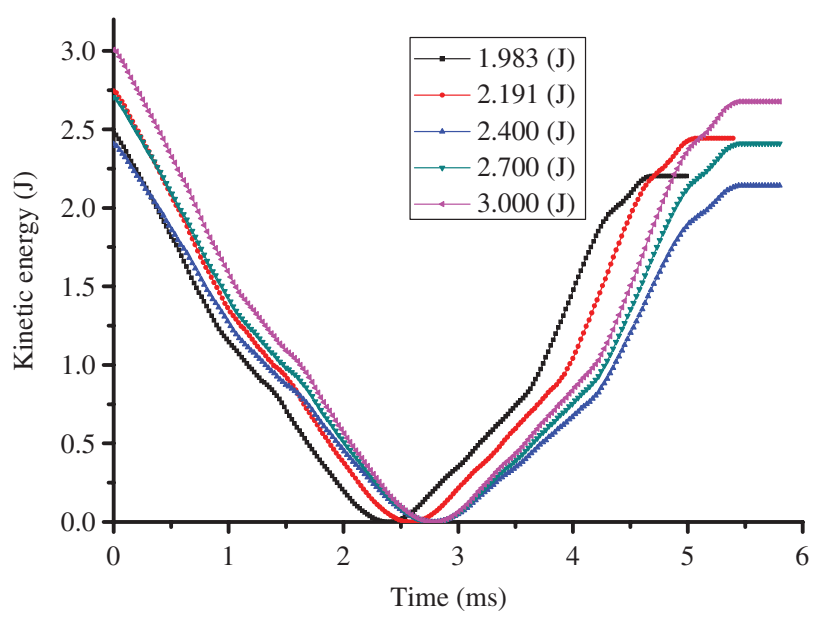

Figure 17: The variations of punch kinetic energy as a function of time.

\subsubsection{Effect of geometric shapes of the punch on adhesive layer damage and plate center displacement}

Table 6 shows that the punch geometric shape does not significantly affect the adhesive layer damage and the plate center displacement. Moreover, the table also shows
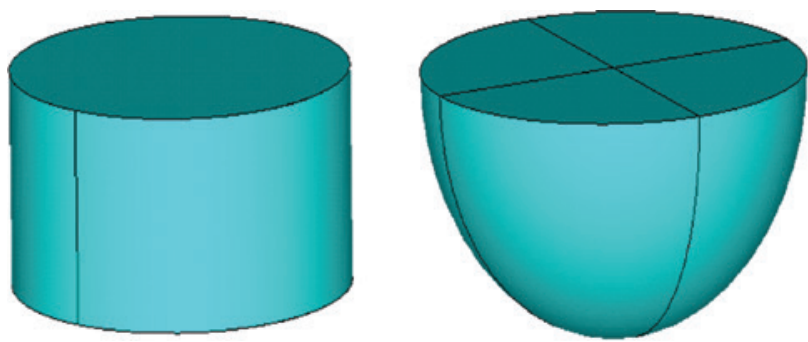

that the more incisive the punch, the more serious the damage to the laminate plate.

\section{Conclusion}

In this paper, the dynamic response of composite laminated plates was studied and simulated under both highand low-velocity impacts. Under high-velocity impact, different types of bullets, acceleration, and energy are analyzed. The results show that the energy absorption of

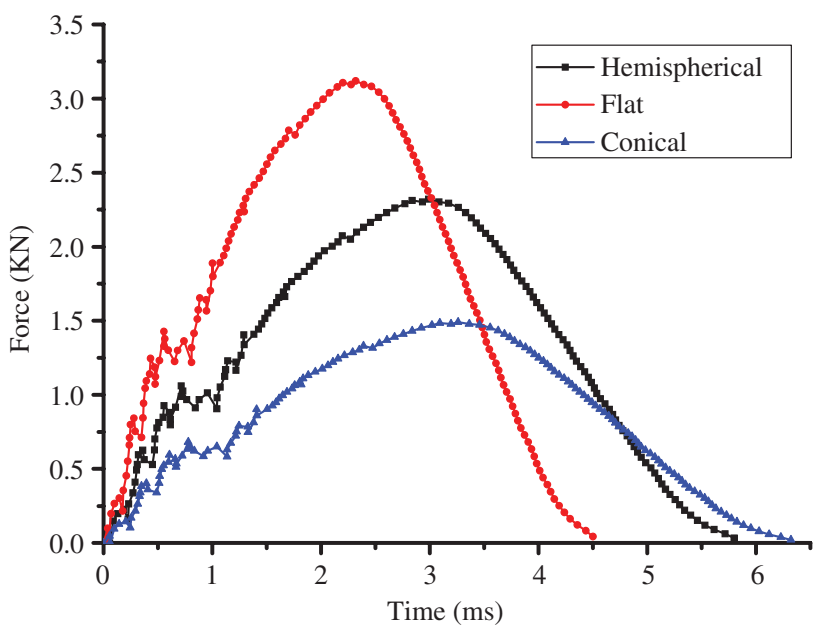

Figure 19: The time curve on the impact contact force with different impactor geometric shapes.

Table 6: The damaged area of the adhesive layer and the maximum displacement of the plate center caused by the punch with different geometric shapes.

\begin{tabular}{lrr}
\hline $\begin{array}{l}\text { The shape of } \\
\text { the punch }\end{array}$ & $\begin{array}{r}\text { The damaged area } \\
\text { of the adhesive } \\
\text { layer }\left(\mathrm{mm}^{2}\right)\end{array}$ & $\begin{array}{r}\text { The maximum } \\
\text { displacement of the } \\
\text { plate's center }(\mathrm{mm})\end{array}$ \\
\hline Flat & 345 & 2.2 \\
Hemispherical & 351 & 2.5 \\
Conical & 362 & 3.02 \\
\hline
\end{tabular}

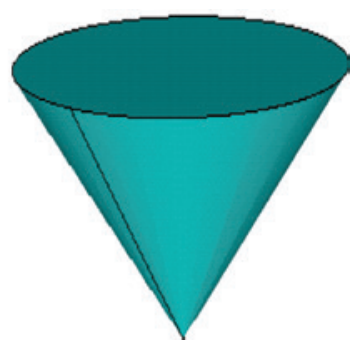

Figure 18: The schematic diagram of the impactor geometric shapes (flat, hemispherical, and conical). 
the studied composite laminates increases with highervelocity impacts, specific energy absorption linearly increases with plate thickness, and the target energy absorption decreases as the layer angle increases.

The contact impact force of laminated plates and the damage evolution of cohesive layer and sub-layers with different angles and under low-velocity impact are discussed. The results show that the maximum contact force, the damage area of adhesive layer, and the displacement of the center of laminated plates increase as the impact energy increases. It also shows that the impact energy is not directly related to impact duration and energy absorption of composite laminates.

The impactors with hemispherical, flat, and conical punches are also discussed. Under the impact of conical punch, the laminated plate experiences the longest contact time, the largest damage area, and the most center displacement. Under the impact of flat punch, the laminated plate experiences the shortest contact time, the smallest damage area, and the least center displacement.

Acknowledgments: This work was supported by the National Natural Science Foundation of China (grant numbers 11702097, 11532013, and 11302054, Funder Id: 10.13039/501100001809) and the Natural Science Foundation of Heilongjiang Province of China (grant number A2015012).

\section{References}

[1] Shim GI, Kim SH, Ahn DL, Park JK, Jin DH, Chung DT, Choi SY. Compos. Part B-Eng 2016, 97, 150-161.

[2] Zhao L, Liu ML. Mater. Res. 2015, 1090, 22-25.

[3] Alderliesten RC. Mater. Design 2015, 66, 421-428.

[4] Wulfsberg J, Herrmann A, Ziegmann G, Lonsdorfer G, Stöß N, Fette M. Procedia Engineer. 2014, 81, 1601-1607.

[5] Shao D, Yu M, Lian J, Sawyer S. Nanotechnology 2013, 24, 295701.

[6] Kim EH, Rim MS, Lee I, Hwang TK. Compos. Struct. 2013, 95, 123-134.

[7] Yang B, He L, Gao Y. Sci. Eng. Compos. Mater. 2017, 25, 621-631.

[8] Yang B, Wang ZQ, Zhou LM, Zhang JF, Liang WY. Compos. Struct. 2015, 132, 464-476.

[9] Long S, Yao X, Zhang X. Compos. Struct. 2015, 132, 290-298.

[10] Zhang C, Duodu EA, Gu J. Compos. Struct. 2017, 173, 219-227.

[11] Zhang J, Zhang X. Compos. Struct. 2015, 130, 85-94.

[12] Yang B, Wang ZQ, Zhou LM, Tong LL, Zhang JF, Liang WY. Compos. Struct. 2015, 132, 1129-1140.

[13] Aymerich F, Dore F, Priolo P. Compos. Sci. Technol. 2009, 69, 1699-1709.

[14] Wang YB, Wang XJ, Hu XZ, Wang F. Engineer. Mechan. 2005, 3, 014.

[15] Aymerich F, Dore F, Priolo P. Compos. Sci. Technol. 2008, $68,2383-2390$.

[16] Tao L, Xue JY, Feng MY, Xiu LZ, Ai L. Eng. Plast. Appl. 2010, 10, 003.

[17] Findik F, Tarim N. Compos. Struct. 2003, 61, 187-192. 